\title{
Comparison of clinical laboratory tests between bacterial sepsis and SARS-CoV-2- associated viral sepsis
}

\author{
Chao Ren ${ }^{1,2,3{ }^{\dagger}}$, Ren-Qi Yao ${ }^{1,2,3{ }^{\dagger}}$, Di Ren ${ }^{1,2+}$, Ying Li ${ }^{1}$, Yong-Wen Feng ${ }^{1 *}$ and Yong-Ming Yao ${ }^{1,3^{*}}$
}

\begin{abstract}
Sepsis is a life-threatening condition that is characterized by multiple organ dysfunction due to abnormal host response to various pathogens, like bacteria, fungi and virus. The differences between viral and bacterial sepsis are indeed of great significance to deepen the understanding of the pathogenesis of sepsis, especially under pandemics of SARS-CoV-2 infection.
\end{abstract}

Keywords: SARS-CoV-2, COVID-19, Sepsis, Bacteria, Virus, Infection, Host response

Dear editor,

The pandemics of severe acute respiratory syndrome coronavirus 2 (SARS-CoV-2) infection have become a world health crisis that cause significant loss of life. The dysregulated host response to SARS-CoV-2 appears to be associated with the severity and poor outcomes of coronavirus disease 2019 (COVID-19) patients [1], hinting the critical involvement of SARS-CoV-2-induced sepsis based on Sepsis 3.0 definition [2-4]. The development of sepsis accounts for one of the leading causes of death in patients admitted to intensive care units (ICU), but evidences on viral sepsis remain scarce in current clinical practices, let alone its differences with bacterial sepsis. Given the pandemics of SARS-CoV-2 infection [5], the differences between viral and bacterial sepsis are indeed of great significance to deepen the understanding of the pathogenesis of sepsis.

In this study, we obtained the clinical data from two cohorts up to May 13, 2020, including 41 critically ill COVID-19 patients from the Third People's Hospital of Shenzhen and 194 non-COVID-19 patients admitted to

\footnotetext{
* Correspondence: fengyongwen2008@126.com; c_ff@sina.com

${ }^{\dagger}$ Chao Ren, Ren-Qi Yao and Di Ren contributed equally to this work.

'Department of Critical Care Medicine, the Second People's Hospital of Shenzhen, Shenzhen 518035, Guangdong, China

Full list of author information is available at the end of the article
}

ICU of the Second People's Hospital of Shenzhen, China. Demographic characteristics, comorbidities, and laboratory findings on ICU admission and clinical outcomes were collected. Sequential Organ Failure Assessment (SOFA) and Acute Physiology and Chronic Health Evaluation II (APACHE II) scores were calculated within the first $24 \mathrm{~h}$ since ICU admission. The bacterial and viral sepsis were identified by blood culture and metagenomic next-generation sequencing.

Twenty-one patients with SARS-CoV-2-induced sepsis and 46 patients with bacterial sepsis were finally recruited (Additional file 2). The median age was 64.0 years (IQR, 60.5-68.0) and 65.5 years (IQR, 49.3-77.3) for patients of SARS-CoV-2-induced sepsis and bacterial sepsis, respectively (Additional file 1). The prognostic scoring system, including SOFA [6.0 (IQR, 4.0-9.0) vs. 4.0 (IQR, 3.5-5.0), $P=0.01]$ and APACHE II [17.0 (IQR, 13.0-20.3) vs. 8.0 (IQR, 6.5-9.5), $P<0.001$ ] were consistently higher among patients with bacterial sepsis than those with SARS-CoV2-induced sepsis. Meanwhile, ICU mortality rates were significantly higher in patients with bacterial sepsis than those with viral sepsis [34.8\% (16/46) vs. $4.8 \%(1 / 21), P=0.013]$.

As presented in Table 1, absolute counts of $\mathrm{T}$ lymphocytes, cytotoxic $\mathrm{T}$ lymphocytes (Tc), and helper $\mathrm{T}$ lymphocytes (Th) were significantly lower among patients 
Table 1 Comparison of laboratory findings between SARS-CoV-2- and bacteria-induced septic patients admitted to ICU

\begin{tabular}{|c|c|c|c|c|c|}
\hline Item & $\begin{array}{l}\text { Normal } \\
\text { range }\end{array}$ & Total $(n=67)$ & $\begin{array}{l}\text { SARS-CoV-2-induced sepsis } \\
(n=21)\end{array}$ & $\begin{array}{l}\text { Bacteria-induced sepsis } \\
(n=46)\end{array}$ & $P$ \\
\hline \multicolumn{6}{|l|}{ Blood routine test } \\
\hline White blood cell counts $\left(\times 10^{9} /\llcorner)\right.$ & $3.5-9.5$ & $9.6(6.1-15.9)$ & $7.0(4.7-10.9)$ & $11.7(6.6-17.3)$ & 0.007 \\
\hline Neutrophil counts $\left(\times 10^{9} / \mathrm{L}\right)$ & $1.8-6.3$ & $9.0(4.3-13.9)$ & $5.8(3.6-8.9)$ & $11.1(5.5-15.3)$ & 0.003 \\
\hline Lymphocyte counts $\left(\times 10^{9} / \mathrm{L}\right)$ & $1.1-3.2$ & $0.7(0.5-1.0)$ & $0.6(0.6-0.8)$ & $0.7(0.5-1.0)$ & 0.68 \\
\hline Neutrophil to lymphocyte ratio & NA & $11.0(4.8-21.5)$ & $9.5(4.5-13.1)$ & $12.2(6.0-24.6)$ & 0.094 \\
\hline Monocyte counts $\left(\times 10^{9} / \mathrm{L}\right)$ & $0.1-0.6$ & $0.4(0.2-0.8)$ & $0.4(0.2-0.5)$ & $0.5(0.2-0.9)$ & 0.311 \\
\hline Platelet counts $\left(\times 10^{9} / \mathrm{L}\right)$ & $125.0-350.0$ & $186.0(141.0-262.0)$ & $181.0(148.5-237.5)$ & $191.0(130.0-284.8)$ & 0.71 \\
\hline Haemoglobin $[\mathrm{g} / \mathrm{L}$, mean $(\mathrm{SD})]$ & $130-175$ & $113.7(26.0)$ & $131.5(17.4)$ & $105.6(25.4)$ & $<0.001$ \\
\hline Hematocrit (\%) & $40.0-50.0$ & $33.8(28.6-37.9)$ & $37.3(34.9-40.4)$ & $30.8(25.6-36.0)$ & $<0.001$ \\
\hline \multicolumn{6}{|l|}{ Coagulation function } \\
\hline Prothrombin time (s) & $10.5-13.5$ & $13.0(11.9-14.1)$ & $13.4(12.3-13.9)$ & $12.9(11.8-14.5)$ & 0.665 \\
\hline Activated partial thromboplastin time (s) & $21.0-37.0$ & $33.9(29.1-40.4)$ & $34.7(32.5-40.2)$ & $32.1(29.0-41.6)$ & 0.402 \\
\hline International normalized ratio & $0.8-1.3$ & $1.1(1.0-1.2)$ & $1.0(0.9-1.1)$ & $1.1(1.0-1.3)$ & 0.002 \\
\hline D-dimer $(\mu \mathrm{g} / \mathrm{L})$ & $0-1.5$ & $3.1(1.6-8.0)$ & $1.1(0.7-2.8)$ & $4.4(2.6-9.6)$ & $<0.001$ \\
\hline \multicolumn{6}{|l|}{ Blood biochemistry } \\
\hline Albumin, median [g/L, mean (IQR)] & $40.0-55.0$ & $30.1(25.6-33.7)$ & $34.6(31.3-36.5)$ & $26.8(24.2-31.6)$ & $<0.001$ \\
\hline Alanine aminotransferase(U/L) & $9.0-50.0$ & $38.0(27.8-60.1)$ & $33.5(22.0-54.3)$ & $43.0(28.8-70.0)$ & 0.241 \\
\hline Aspartate aminotransferase $(U / L)$ & $15.0-40.0$ & $48.4(31.8-91.3)$ & $47.0(32.6-69.5)$ & $48.5(29.3-100.8)$ & 0.567 \\
\hline Total bilirubin ( $\mu \mathrm{mol} / \mathrm{L})$ & 0.21 .0 & $15.7(10.7-22.2)$ & $20.7(12.8-27.6)$ & $15.4(8.6-21.0)$ & 0.025 \\
\hline Serum creatinine $(\mu \mathrm{mol} / \mathrm{L})$ & $57.0-111.0$ & $77.0(50.2-124.4)$ & $75.1(56.3-92.7)$ & $77.0(48.3-155.1)$ & 0.727 \\
\hline Blood urea nitrogen $(\mathrm{mmol} / \mathrm{L})$ & $3.6-9.5$ & $7.1(5.4-9.6)$ & $6.6(5.5-8.3)$ & $7.4(5.3-12.8)$ & 0.151 \\
\hline Creatine kinase MB form $(\mathrm{U} / \mathrm{L})$ & $0-5.0$ & $2.0(1.1-5.0)$ & $0.8(0.4-1.9)$ & $2.8(2.0-7.6)$ & $<0.001$ \\
\hline NT-pro BNP (pg/ml) & $0-125.0$ & $1778.5(223.8-6170.5)$ & $133.5(71.8-772.0)$ & 3298.5 (473.8-7077.5) & $<0.001$ \\
\hline Lactate dehydrogenase (U/L) & $120.0-350.0$ & $749.0(427.0-1290.0)$ & $693.0(399.0-883.5)$ & $936.5(490.8-1535.5)$ & 0.089 \\
\hline \multicolumn{6}{|l|}{ Arterial blood gas } \\
\hline Sodium (mmol/L) & $135.0-145.0$ & $136.0(132.0-141.0)$ & $135.2(132.5-141.6)$ & $136.0(131.8-141.0)$ & 0.797 \\
\hline Potassium (mmol/L) & $3.5-5.0$ & $3.6(3.4-4.1)$ & $3.5(3.2-3.6)$ & $3.8(3.5-4.3)$ & 0.02 \\
\hline Chloride (mmol/L) & $90.0-110.0$ & $101.0(97.8-106.0)$ & $101.0(98.0-106.5)$ & $101.0(96.8-105.3)$ & 0.695 \\
\hline $\mathrm{PaO}_{2}(\mathrm{mmHg})$ & $83.0-108.0$ & $81.0(61.4-99.6)$ & $65.3(57.5-82.0)$ & $86.5(64.6-130.0)$ & 0.02 \\
\hline $\mathrm{PaCO}_{2}(\mathrm{mmHg})$ & $35.0-48.0$ & $33.6(30.7-40.6)$ & $33.3(31.4-36.6)$ & $34.0(28.8-44.9)$ & 0.72 \\
\hline $\mathrm{PaO}_{2}: \mathrm{FlO}_{2}(\mathrm{mmHg})$ & $400.0-500.0$ & $162.2(119.4-219.3)$ & $132.9(116.2-174.9)$ & $181.3(119.0-279.9)$ & 0.07 \\
\hline Glucose (mmol/L) & $3.9-6.1$ & $9.2(6.8-13.8)$ & $11.1(8.3-14.9)$ & $8.8(5.9-13.0)$ & 0.155 \\
\hline Lactate (mmol/L) & $0.5-1.6$ & $2.1(1.5-2.9)$ & $2.5(1.6-3.0)$ & $2.0(1.5-2.6)$ & 0.226 \\
\hline \multicolumn{6}{|l|}{ Immune-related biomarkers } \\
\hline Absolute T lymphocyte counts (count/ $\mu \mathrm{l}$ ) & NA & $440.0(329.5-581.0)$ & $329.5(313.3-472.3)$ & $492.0(382.0-720.0)$ & 0.004 \\
\hline Absolute helper T lymphocyte counts (count/Ml) & NA & $246.0(188.0-372.0)$ & $201.0(156.0-264.5)$ & $308.0(208.0-420.0)$ & 0.034 \\
\hline Absolute cytotoxic T lymphocyte counts (count/Ml) & NA & $152.0(102.0-236.0)$ & $101.0(91.0-153.8)$ & $180.0(132.0-264.0)$ & 0.003 \\
\hline CD4/CD8 ratio [mean (SD)] & $0.9-3.6$ & $1.8(0.9)$ & $1.9(0.9)$ & $1.8(0.9)$ & 0.709 \\
\hline \multicolumn{6}{|l|}{ Inflammation-related biomarkers } \\
\hline C-reactive protein (mg/L) & $0-10.0$ & $104.7(30.9-148.4)$ & $119.2(70.7-154.6)$ & $37.2(23.8-111.6)$ & 0.008 \\
\hline Procalcitonin (ng/ml) & $0-5.0$ & $0.5(0.2-3.8)$ & $0.2(0.2-0.3)$ & $1.4(0.3-5.5)$ & $<0.001$ \\
\hline
\end{tabular}

Data were median (IQR) if not otherwise specified. $\mathrm{n}(\%)$ referred to the total number of patients with available data. $P$ values indicated differences between SARS-CoV-2-induced sepsis and bacteria-induced sepsis, in which $P<0.05$ was deemed as statistical significance

SD Standard deviation, BNP Brain natriuretic peptide, NA Not applicable 
with SARS-CoV-2-induced sepsis at ICU admission, while elevated inflammation-related parameters, C-reactive protein (CRP) as an example, were observed in this cohort compared to patients with bacterial sepsis. In addition, obvious differences in organ functional parameters were noted between the two cohorts, including significantly increased levels of creatine kinase-MB and NT-pro BNP, and decreased albumin level in patients with developed bacterial sepsis.

In this study, ICU patients with SARS-CoV-2-induced sepsis and those with bacterial sepsis revealed comparable demographic characteristics, like age, gender distribution, and comorbidities, after rigorous screening processes. However, patients with bacterial sepsis were found with more severe organ dysfunction and poor outcomes when compared with those caused by SARS-CoV-2-induced sepsis, including higher values in SOFA and APACHE II, as well as more ICU deaths. The different patterns of immune responses might be the major cause of the divergent outcomes between viral and bacterial sepsis. We further found that failed homeostasis was characterized in both bacterial and viral sepsis but triggered by different pathogens. In the development of viral sepsis, the loss of $\mathrm{T}$ lymphocytes and their subsets was the dominant characteristics of dysregulated immune response, thereby contributing to the imbalance between innate and adaptive immune systems; while excessive inflammatory activation was the main feature of bacterial sepsis, which further resulted in intractable immune suppression and multiple organ dysfunction. This is the first report that compared clinical features and host responses between bacterial and SARS-CoV-2-induced viral sepsis. These findings might not only suggest divergent host responses to bacteria and virus but also provide novel insights into further researches on the development of sepsis with underlying etiology of various pathogens.

\section{Supplementary information}

Supplementary information accompanies this paper at https://doi.org/10. 1186/s40779-020-00267-3.

Additional file 1. Appendix Table 1. Baseline characteristics of critically ill patients with SARS-CoV-2- and bacteria-induced sepsis.

Additional file 2. Appendix Figure 1. Flow diagram of patient inclusion. COVID-19: Coronavirus disease 2019; SARS-CoV-2: Severe acute respiratory syndrome coronavirus 2; SOFA: Sequential organ failure assessment; ICU: Intensive care unit; LOS: Length of stay; CAP: Community-acquired pneumonia.

\section{Abbreviations}

COVID-19: Coronavirus disease 2019; CAP: Community-acquired pneumonia CRP: C-reactive protein; ICU: Intensive care units; SARS-CoV-2: Severe acute respiratory syndrome coronavirus 2; SOFA: Sequential organ failure assessment; APACHE II: Acute physiology and chronic health evaluation II

\section{Authors' contributions}

All corresponding and first authors contributed to the study concept and design. CR and RQY analyzed the data and drafted this letter. DR and YL recruited patients and extracted epidemiological and clinical data. All authors reviewed and approved the final manuscript.

\section{Funding}

This work was supported by the National Natural Science Foundation of China (81730057 by YMY, 81801935 by CR), Sanming Project of Medicine in Shenzhen (SZSM20162011 by YMY and YWF), and the Military Medical Innovation Program of Chinese PLA (18CXZ026 by YMY).

Availability of data and materials

All data were presented in this manuscript or Appendix.

Ethics approval and consent to participate

This study was approved by the Committee on the Ethics of Medicine, the Second People's Hospital of Shenzhen, China (20200601026).

Consent for publication

Not applicable.

\section{Competing interests}

We declare no competing interests.

\section{Author details}

${ }^{1}$ Department of Critical Care Medicine, the Second People's Hospital of Shenzhen, Shenzhen 518035, Guangdong, China. ²Department of Critical Care Medicine, the Third People's Hospital of Shenzhen, Shenzhen 518020, Guangdong, China. ${ }^{3}$ Trauma Research Center, the Fourth Medical Center and Medical Innovation Research Department of the Chinese PLA General Hospital, Beijing 100048, China.

Received: 16 July 2020 Accepted: 29 July 2020

Published online: 04 August 2020

References

1. Xu Z, Shi L, Wang YJ, Zhang JY, Huang L, Zhang C, et al. Pathological findings of COVID-19 associated with acute respiratory distress syndrome. Lancet Respir Med. 2020. https://doi.org/10.1016/S2213-2600(20)30076-X

2. Singer M, Deutschman CS, Seymour CW, Shankar-Hari M, Annane D, Bauer $M$, et al. The third international consensus definitions for sepsis and septic shock (Sepsis-3). JAMA. 2016;315(8):801-10. https://doi.org/10.1001/jama. 2016.0287.

3. Li H, Liu L, Zhang D, Xu J, Dai H, Tang N, et al. SARS-CoV-2 and viral sepsis: observations and hypotheses. Lancet. 2020;395(10235):1517-20. https://doi. org/10.1016/S0140-6736(20)30920-X.

4. Ren D, Ren C, Yao RQ, Feng YW, Yao YM. Clinical features and development of sepsis in patients infected with SARS-CoV-2: a retrospective analysis of 150 cases outside Wuhan, China. Intensive Care Med. 2020:1-4. https://doi. org/10.1007/s00134-020-06084-5

5. Jin $Y H$, Cai $L$, Cheng $Z S$, Cheng $H$, Deng $T$, Fan $Y P$, et al. A rapid advice guideline for the diagnosis and treatment of 2019 novel coronavirus (2019nCoV) infected pneumonia (standard version). Mil Med Res. 2020;7:4.

Ready to submit your research? Choose BMC and benefit from:

- fast, convenient online submission

- thorough peer review by experienced researchers in your field

- rapid publication on acceptance

- support for research data, including large and complex data types

- gold Open Access which fosters wider collaboration and increased citations

- maximum visibility for your research: over $100 \mathrm{M}$ website views per year

At BMC, research is always in progress.

Learn more biomedcentral.com/submission 